\title{
Multiple control of alternative oxidase 1 in Chlamydomonas reinhardtii under phosphorus deprivation
}

\author{
Reem Alqoubaili, Vitalina Derkach and Elena Ermilova \\ Department of Microbiology, St. Petersburg State University, 199178, St. Petersburg, \\ Russia
}

| Submitted August 20, $2021 \mid$ Accepted September 17, 2021 |

\begin{abstract}
Summary
The mitochondrial respiratory chain in various protists, many fungi and all plants consists of the ATP-coupling cyanide-sensitive cytochrome pathway and the cyanide-resistant alternative non-phosphorylating electron transport pathway. The alternative pathway reduces $\mathrm{O}_{2}$ to $\mathrm{H}_{2} \mathrm{O}$, and this is mediated by a terminal alternative oxidase (AOX). The unicellular green alga Chlamydomonas reinhardtii reacts to phosphorus $(\mathrm{P})$ limitation conditions with the induced expression of many genes among which only one, $A O X 1$, encodes mitochondrial protein. In this study, we demonstrated a sharp increase in AOX1 protein abundance and AOX capacity under P deprivation. Our data revealed that PSR1 transcription factor is not the only regulator of $A O X 1$ during $\mathrm{P}$ deprivation. Using biochemical and molecular-genetic approaches, we showed that AOX1 is tuned at transcriptional and post-transcriptional levels, and nitric oxide is an integral part of this regulation. The previously unidentified links between AOX1 synthesis and its capacity, and the truncated hemoglobin 2 (THB2)-dependent pathway could unveil the mechanism by which the alternative respiratory pathway is integrated into the acclimation of cells to stress conditions.
\end{abstract}

Key words: alternative oxidase, Chlamydomonas, nitric oxide, phosphorus deprivation, truncated hemoglobin

\section{Introduction}

The mitochondrial respiratory chain in various protists, many fungi and all plants consists of the ATP-coupling cyanide-sensitive cytochrome pathway and the cyanide-resistant alternative nonphosphorylating electron transport pathway (Finnegan et al., 2004; McDonald, 2008; Millar et al., 2011). The alternative pathway reduces $\mathrm{O}_{2}$ to $\mathrm{H}_{2} \mathrm{O}$, and this is achieved by a terminal alternative oxidase

doi:10.21685/1680-0826-2021-15-3-6
(AOX). Since many factors inhibit the activity of the cytochrome oxidase (COX), electrons flowing to AOX bypass the proton pumping complexes III and IV of the cytochrome pathway, allowing respiration to continue under COX restriction (Vanlerberghe, 2013).

$\mathrm{AOX}$ is an ubiquinol oxidase, which is located in the inner mitochondrial membrane. Based on structural and regulatory differences, two types of AOX proteins are distinguished: homodimeric plant type and monomeric fungi-type (Affourtit et 
al., 2002). In Chlamydomonas reinhardtii (Chlamydomonas in the following), AOXs are fungi-type proteins encoded by two nuclear encoded genes of discrete subfamilies, $A O X 1$ and $A O X 2$ (Dinant et al., 2001; Baurain et al., 2003). Chlamydomonas $A O X 1$ and $A O X 2$ are located in chromosome 9 and chromosome 3 , respectively.

In higher plants, the $A O X$ genes are induced in response to various stimulants (Van Aken et al., 2009; Vanlerberghe et al., 2009). Most of the research has focused on AOX1 isoforms, since in most plants these are the predominant forms (Selinski et al., 2018). Interestingly, in Chlamydomonas, $A O X 1$ is also expressed at a higher level than $A O X 2$ (Molen et al., 2006). Importantly, the $A O X 1$ is clustered with the genes required for nitrate assimilation (Quesada et al., 1998; Dinant at al., 2001), and this gene is induced by nitrate and repressed by ammonium (Molen et al., 2006). In addition, both the AOXI gene (Molen et al., 2006; Zalutskaya et al., 2015, 2016) and the $A O X 2$ gene (Ostroukhova et al., 2017) are significantly expressed upon stress conditions. Moreover, $A O X 1$ is upregulated when availability of macronutrients is scarce (Moseley et al., 2006; Zalutskaya et al., 2018).

Phosphorus, in the form of phosphate $(\mathrm{P})$, is an essential macronutrient for all organisms, including Chlamydomonas. Upon P-deprivation, this unicellular alga uses a variety of strategies to improve acquisition, utilization, and conservation of $\mathrm{P}$ (Moseley and Grossman, 2009). Among the transcripts encoding known mitochondrial proteins, only $A O X 1$ is significantly upregulated in P-starved cells (Moseley et al., 2006). PSR1 (P starvation response 1 regulator) is the most critical regulator in the process of Chlamydomonas acclimation to P limitation (Wykoff et al., 1999; Moseley et al., 2006). Recently, a tight regulatory link between the truncated hemoglobin 2 (THB2)-controlled nitric oxide (NO) levels and PSR1-dependent regulation of several P-deprivation responsive genes with various roles has been identified in the Chlamydomonas cells during P limitation (Grinko et al., 2021). Notably, AOX1 is a target of NO in this alga (Zalutskaya et al., 2017). However, it is not known yet whether different signals are integrated for regulation of AOX1 upon $\mathrm{P}$ deprivation. This prompted us to test which regulators control the AOX1 synthesis and activity in P-depleted Chlamydomonas cells. This work integrates the key roles of PSR1, NO and THB2 in regulating of AOX1 synthesis and capacity.

\section{Material and methods}

\section{STRAINS AND GROWTH CONDITIONS}

The Chlamydomonas strain cw15-325 ( mt + cw15 $\arg 7$ ) was kindly provided by Prof. Michael Schroda (Technical University of Kaiserslautern, Germany). The strains amiRNA-THB2-30, amiRNATHB2-46, and amiRNATHB2-68, in which the transcript levels of $T H B 2$ were $11 \%, 17 \%$, and $8 \%$ of those in the parental cells, were generated previously (Grinko et al., 2021). The strain CC-4267 (psr1-1 $m t$-) was obtained from Chlamydomonas Resource Center(USA). Cells were grown in tris-acetate-phosphate (TAP) medium (http://www.chlamy.org/ TAP.html) under continuous illumination by white light (fluence rate of $45 \mu \mathrm{mol} \mathrm{m}^{-2} \mathrm{~s}^{-1}$ ) at $22^{\circ} \mathrm{C}$ with a constant orbital agitation at $90 \mathrm{rpm}$. The TAP medium was supplemented with $100 \mathrm{mg} / \mathrm{l}$ arginine when required.

To induce phosphorus starvation, the cells grown in TAP medium were collected at the midexponential phase of growth by centrifugation $(4000 \times \mathrm{g}, 5 \mathrm{~min})$, washed twice with phosphorus-free medium (TA), and then incubated in TA. The P-free medium was prepared as reported previously (Moseley et al., 2009). At each harvesting time, the number of cells was recorded by employing a counting chamber. Four-hundred cells from each sample were scored for three biological replicates. The number of viable cells was counted microscopically with the use of $0.05 \%$ (v/v) Evans blue (DIA-M, Russia) as described earlier (Baker and Mock, 1994). The number of non-viable (stained) and viable (unstained) cells were determined. 2-(N,Ndiethylamino)-diazenolate 2-oxide sodium salt (DEA-NONOate, Sigma-Aldrich, USA) and S-Nitroso-N-acetylpenicillamine (SNAP, SigmaAldrich, USA) were used at final concentrations of $100 \mu \mathrm{M}$ and $2 \mathrm{mM}$, respectively.

\section{QuANTITATIVE REAL-TIME PCR}

The total RNA was isolated with Trizol according to the manufacturer's instructions (Invitrogen, USA). The RNA samples were treated with RNaseFree DNase I (Fermentas) to remove genomic DNA. Subsequently, RNA concentration and purity (260/ $280 \mathrm{~nm}$ ratio) were determined using a spectrophotometer (SmartSpec Plus, Bio-Rad). Reverse transcription was performed with Revert Aid H Mi- 
nus First Strand cDNA Synthesis Kit according to the manufacturer's instructions (Thermo Scientific, USA). The primer pairs used for real time qPCR were as follows: $5^{6}$ - ACTTGGATCTGTGTGCCTGG $-3^{6}$ and $5^{6}$ - CTGGGCCGGTATCTACGTTC-3 ${ }^{6}$ for $A O X 1$ (Cre09.g395950); and 5'-CTTCTCG CCCATGACCAC-3' and 5'-CCCACCAGGT TGTTCTTCAG-3' for RACK1. Real time qPCR was performed on the Light Cycler Instrument (CFX96 Real-Time PCR Detection System, Bio Rad) using SYBR Green I as described earlier (Zalutskaya et al., 2016). Gene expression ratios were normalized to $R A C K 1$ (receptor of activated protein kinase $\mathrm{C}$; Cre13.g599400) using the $\Delta \Delta \mathrm{Ct}$ method (Livak and Schmittgen, 2001). DEA-NONOate and SNAP treatments had no effect on the accumulation of RACK1 transcripts in the Chlamydomonas cells. The accuracy and reproducibility of the real-time assay was determined from low variation in $\mathrm{C}_{\mathrm{T}}$ values across replicates. Values were obtained from at least three biological replicates; each replicate was analyzed three times. Student's tests were used for statistical comparisons. P-values of $<0.05$ were considered significant.

\section{Protein ISOLATION ANd Western bLOtTING ANALYsis}

The Chlamydomonas cells $\left(2-410^{6}\right.$ cells $\mathrm{ml}^{-1}$ in $10 \mathrm{ml}$ ) were collected by centrifugation $(3,000$ $\mathrm{g}, 5 \mathrm{~min}$ ) and resuspended in $0.1 \mathrm{M} \mathrm{DTT}, 0.1 \mathrm{M}$ $\mathrm{Na}_{2} \mathrm{CO}_{3}$. Then, $0.66 \mathrm{vol}$ of $5 \%$ SDS, $30 \%$ sucrose were added. Homogenization of the suspensions was achieved by rapid shaking at room temperature for $20 \mathrm{~min}$. The protein concentration was determined by staining with amido black, using BSA as a standard (Popov et al., 1975). After separation of the proteins by SDS-PAGE on a $12 \%$ polyacrylamide gel (Laemmli, 1970), they were transferred to nitrocellulose membranes (Carl Roth, Karlsruhe) by a semidry blotting (Trans-blot SD BioRad) and then membranes were stained with Ponseau S staining solution $(0.1 \%(\mathrm{w} / \mathrm{v}))$ for $5 \mathrm{~min}$ with gentle agitation. The stained and rinsed in distilled water membranes were then blocked in 5\% non-fat dry milk in Trisbuffered saline solution with $0.1 \%$ Tween 20 prior to an incubation during $1 \mathrm{~h}$ in the presence of primary antibodies. The dilution of the primary antibody was 1:10,000 anti-AOX1 (Agrisera, Sweden, Cat\#AS06 152). A 1:10,000 dilution of horseradish peroxidaseconjugated anti-rabbit serum (Sigma) was used as a secondary antibody. The peroxidase activity was detected by an enhanced chemiluminescence assay
(Roche). The films were scanned using Bio-Rad ChemiDocTMMP Imaging System.

\section{RESPIRATION MEASUREMENTS}

Cellular respiratory rates were measured as oxygen uptake in the dark at $22{ }^{\circ} \mathrm{C}$ using a Clark-type oxygen electrode (Dissolved Oxygen Meter, Hanna, HI-5421). Oxygen consumption rates were monitored as described by Zalutskaya et al. (2015). The calculation of the AOX respiration capacity was the rate of oxygen consumption in the presence of the cytochrome pathway inhibitor $2 \mathrm{mM} \mathrm{KCN}$ (Maxwell et al., 2002). The residual rate of oxygen consumption in the presence of both $\mathrm{KCN}$ and 2 mM salicylhydroxamic acid (SHAM) (Aldrich, USA) was subtracted from all measurements of total and AOX pathway respiration. Measurements were performed on three separate cultures (biological repeats) of each strain.

\section{Results}

$A O X 1$ GENE EXPRESSION BUT NOT AOX1 PROTEIN ACCUMULATION IS SUPPRESSED IN THE PSR 1 MUTANT UNDER P LIMITATION

Previous transcriptomic analysis has identified that the $A O X 1$ gene was induced by $\mathrm{P}$ starvation (Moseley et al., 2006). Indeed, in the P-starved cw15-325 cells, the $A O X 1$ transcript levels increased after 6 h (Fig.1, A). During further exposure to $\mathrm{P}$ limitation, the gene transcription increased and the highest level about 24 times that of the control was reached at $72 \mathrm{~h}$. In addition, $\mathrm{P}$ deprivation resulted in an enhanced abundance of AOX1 protein (Fig. $1, \mathrm{~B})$.

$A O X 1$ gene was found to be a target of PSR1 regulator (Moseley et al., 2006). As expected, the P-deficient psr 1 cells demonstrated only transient increase in $A O X 1$ transcripts after $24 \mathrm{~h}$ of P starvation (approximately 1.7-fold), but this increase was not maintained.

We subsequently tested whether the accumulation of AOX1 protein in the psr 1 strain was also suppressed. Surprisingly, this mutant did not fail to activate an increase in AOX1 in the absence of $\mathrm{P}$ (Fig. 1, B). In the P-deprived mutant cells, the same trends were observed, but the levels of AOX1 protein were lower than those in wild type (WT). 
A

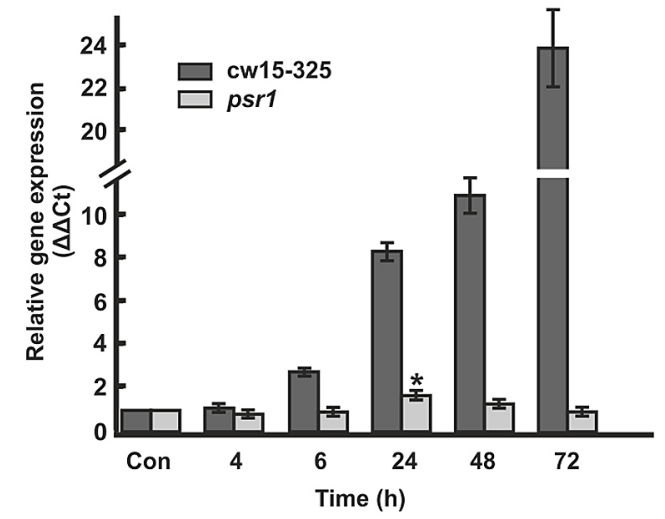

B

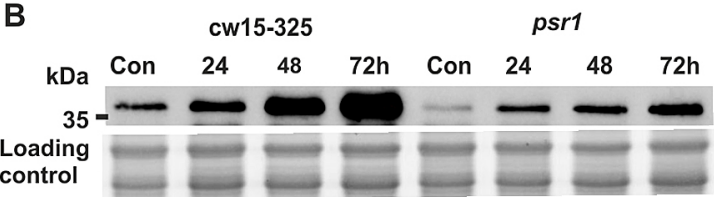

C

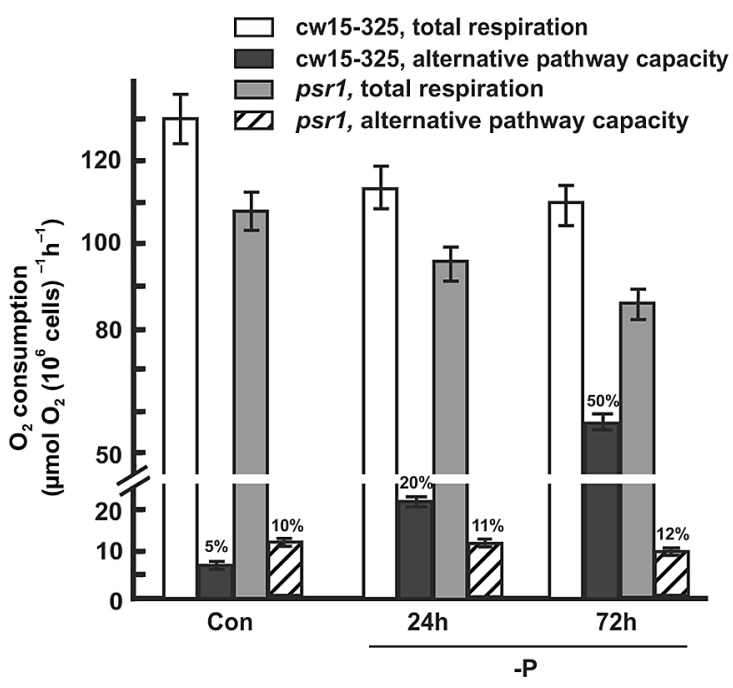

Fig. 1. Effects of $\mathrm{P}$ deprivation on $A O X 1$ transcript accumulation, $\mathrm{AOX} 1$ protein abundance and alternative respiration. A - Levels of $A O X 1$ gene transcripts are calculated as times of relative abundance with respect to the housekeeping control gene ( $R A C K 1)$, which has a value of 1 . Data are the means \pm SE from three biological and three technical replicates obtained by RT-qPCR. * denotes significant differences between variants (TAP and TA) according to the Student's t test $(P$-value $<0.05)$. B - Time course of the AOX1 protein accumulation during incubation of the cw15-325 and psr 1 cells in P-free medium. Protein levels were analyzed by Western blotting in the same conditions as in (A). Each line corresponds to $20 \mu \mathrm{g}$ of soluble proteins extracted from samples taken from cultures at the time points indicated. $\mathrm{C}$ - Oxygen consumption rates were used to measure total respiration and alternative pathway capacities. AOX respiration capacity was detected by the sequential addition of $2 \mathrm{mM} \mathrm{KCN}$ and $2 \mathrm{mM}$ SHAM. $\mathrm{O}_{2}$ uptake rates in the dark were analyzed using a Clark-type $\mathrm{O}_{2}$ electrode. Values represent three biological replicates and at least three technical replicates for each measurement. The data are the means \pm SE.

These results raised the question as to whether the level of AOX1 protein is correlated with AOXdependent respiration. The AOX respiration capacity was measured in cells of the cw15-325 and psr 1 strains in the presence of $2 \mathrm{mM} \mathrm{KCN} \mathrm{(Fig.} \mathrm{1,} \mathrm{C).}$ Before exposure to $\mathrm{P}$ deprivation, AOX respiration capacity was almost the same in both strains and reached 7-10 $\mathrm{O}_{2} \mu \mathrm{mol} / \mathrm{cells} 10^{6} \mathrm{~h}$. Notably, the depletion of $\mathrm{P}$ from the medium affected the total respiration rate in cells. Meanwhile, in the $\mathrm{P}$-starved WT cells AOX respiration capacity markedly increased by approximately $20 \%$ and $50 \%$ compared with that in the control cells. This capacity is reflective of AOX1 protein abundance (Fig. 1, B, C). In contrast, the AOX capacity for the psr 1 strain was stable at all time points after exposing the cells to $\mathrm{P}$ limitation. These data suggest the importance PSR1-independent control of AOX1 synthesis in maintaining AOX respiratory pathway, which, in turn, is required to sustain the electron flow in mitochondria when the total respiration decreased.

NO is InVolved in P-Deprivation induced AOX1 EXPRESSION

Given that NO upregulates expression of AOX1 in Chlamydomonas (Zalutskaya et al., 2017), we wondered whether NO could accumulatively act with P-deficiency-dependent signal to activate the $A O X 1$ gene. Using two NO-donors (DEANONOate and SNAP), we demonstrated that NO strongly increased the $A O X 1$ transcription compared with P-deprived cells (Fig. 2), confirming the combined effect of NO-dependent and PSR1dependent pathways. Taken together, these results suggest that $\mathrm{NO}$ is involved in upregulation of $A O X 1$ in cells transferred to $\mathrm{P}$-deficient conditions. 


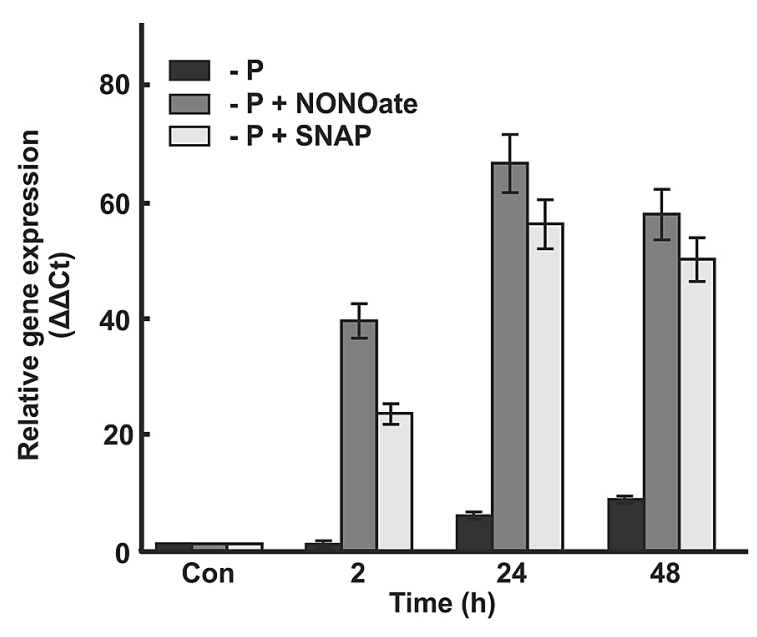

Fig. 2. Effects of DEA-NONOate and SNAP on the P-deprived-induced expression of $A O X 1$ gene. Cells grown in TAP were washed in $\mathrm{P}$-free medium and incubated for $2 \mathrm{~h}, 24 \mathrm{~h}$ or $48 \mathrm{~h}$. DEANONOate $(100 \mu \mathrm{M})$ or SNAP $(2 \mathrm{mM})$ were added $40 \mathrm{~min}$ before the indicated times. Relative gene expression was determined as described in Fig. 1,

A. The data are the means \pm SE.

THB2-UNDEREXPRESSION AFFECTS THE TRANSCRIPT AND PROTEIN LEVELS OF AOX1 DURING P DEPRIVATION

Like some higher plants (Royo et al., 2015), $\mathrm{P}$ deprivation increased NO production in Chlamydomonas (Filina et al., 2019). Since truncated hemoglobin (THB2) is involved in fine-tuning of PSR1-dependent gene expression during P deprivation (Grinko et al., 2021), we next asked whether the effect of $\mathrm{NO}$ on $A O X 1$ expression could be translated via THB2-dependent pathway. To test this hypothesis, three THB2-underexpressing strains, amiRNA-THB2-30, amiRNA-THB2-46, and $a m i$ RNA- THB2-68 (Grinko et al., 2021), were analyzed. We found that incubating in TA medium resulted in decreased $A O X 1 \mathrm{mRNA}$ abundances in all amiRNA-THB2 strains compared with parental strain (Fig. 3, A), which is consistent with the observed inhibitory effect of NO on PSR1 expression (Grinko et al., 2021). This result is in agreement with the fact that AOX1 protein content was increased in THB2-transformants with a delay relative to WT under P-deficient conditions (Fig. 3, B). Notably, the AOX1 protein levels were similar in THB2-cells and WT after $72 \mathrm{~h}$ of P deprivation. Taken together, these results strengthen the idea that several factors related to NO may contribute to regulate the AOX1 expression.
EFFECT OF P DEPRIVATION ON RESPIRATION OF AMIRNATHB2 STRAINS

To further explore the relationship between regulation of AOX1 abundance, THB2 levels and AOX-dependent respiration in P-starved cells, we measured $\mathrm{O}_{2}$ uptake rates in the parental and am $i$ RNA-THB2 strains. Interestingly, the rates of total respiration in the THB2-underexpressing cells were similar to those in WT cells (Fig. 4, A). However, we did not observe a notable increase in alternative respiration when the transformants were deprived of $\mathrm{P}$ for $24 \mathrm{~h}$. Moreover, amiRNATHB2-30, $a m i \mathrm{RNA}-\mathrm{THB} 2-46$ and $a m i \mathrm{RNA}-$ THB2-68 cells showed approximately $54 \%, 28 \%$ and $68 \%$ reduction in AOX capacity relative to that in WT after $72 \mathrm{~h}$ of P limitation (Fig. 4, B). Therefore, although, there is no direct correlation between AOX1 protein content and its activity in respiration (Fig. 3, B and Fig. 4, B), the amiRNA-THB2 strains exhibited decreased rates of AOX respiration compared with WT, suggesting that NO interacts with PSR1-depenent control during P deprivation.

\section{Discussion}

The regulation of the alternative oxidase pathway under nutrient deficiency is important for understanding how respiration modulates ATP synthesis and carbon economy in cells. Although P is a key element for carbon and energy metabolism, and AOX1 gene is up-regulated in the $\mathrm{P}$-deprived Chlamydomonas cells (Moseley et al., 2006), the control of AOX1 synthesis and its activity by $\mathrm{P}$ limitation is still not fully understood. The present research was based on the hypothesis that during exposure to $\mathrm{P}$ starvation, AOX1 is under complex regulation at different levels.

PSR1 controls transcription of the $A O X 1$ gene in the cells suffering from $\mathrm{P}$ deficiency (Fig. 1, A; Moseley et al., 2006). Further Western blotting analysis revealed that $\mathrm{AOX} 1$ protein accumulated in the psr1-defective mutant (Fig. 1, B). This implies that AOX1 is also under post-transcriptional regulation.

As in higher plants (Gonzàlez-Meler et al., 2001; Del-Saz et al., 2017), contribution of the AOX pathway to total respiration increased in Chlamydomonas when $\mathrm{P}$ was limited (Fig. 1, C). Importantly, increases in AOX1 protein levels are correlated with increases in cyanide-resistant respiration rates in WT, but not in the psr 1-deficient 
A

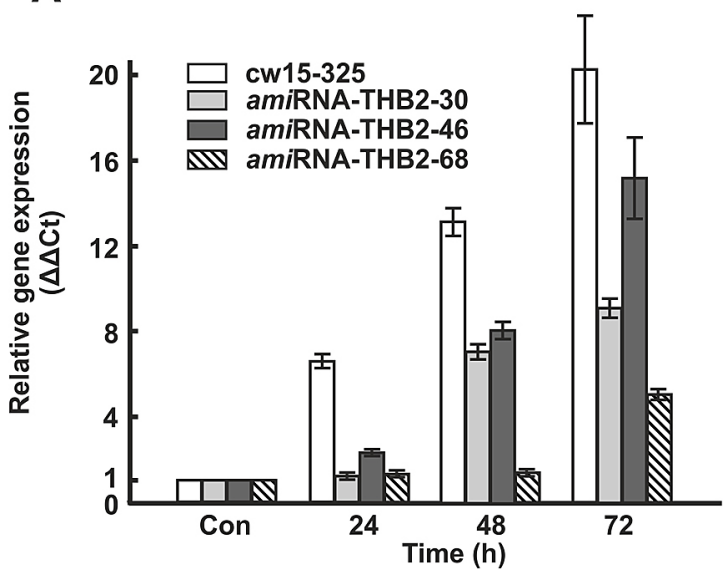

B
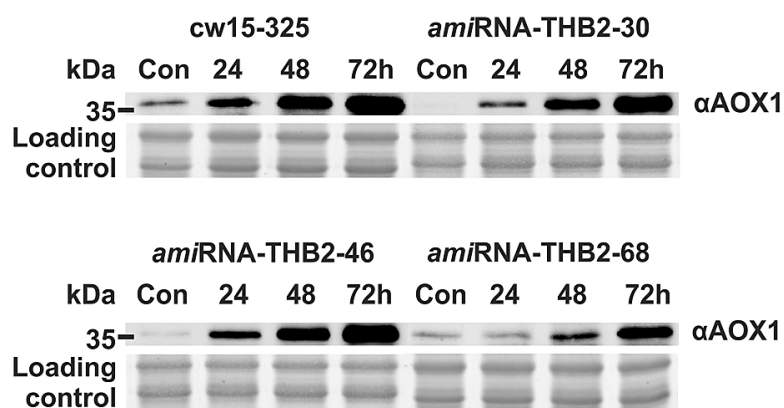

Fig. 3. Effects of $\mathrm{P}$ deprivation on $A O X 1$ transcript accumulation and $\mathrm{AOX} 1$ protein abundance in the cw15325 and amiRNA-THB2 cells. A - Levels of $A O X 1$ gene transcripts are calculated as described in Fig. 1, A. The data are the means \pm SE. B - Time course of the AOX1 protein accumulation. Protein levels were analyzed by Western blotting in the same conditions as in (A). Each line corresponds to $20 \mu \mathrm{g}$ of soluble proteins extracted from samples taken from cultures at the time points indicated.

mutant. However, since psr 1 cells continue to synthesize AOX1 protein, which is used to perform alternative respiration (Fig. 1, B, C), PSR1 factor is not the only regulator of $A O X 1$ during $\mathrm{P}$ deprivation. This is the first report to demonstrate the $-\mathrm{P}$ induced AOX1 protein levels and AOX capacity in addition to PSR1-dependent transcriptional control.

In higher plants, transcriptional control of genes from the $A O X 1$ subfamily is influenced by various regulatory components (Vanlerberghe, 2013; DelSaz et al., 2018a). In this study, we demonstrated that in Chlamydomonas, $\mathrm{NO}$ acts in an additive manner with the PSR1-dependent pathway, to upregulate AOX1 expression in WT (Fig. 2). Therefore, similar to higher plants (Royo et al., 2015), NO generated during P deprivation (Filina et al., 2019; Grinko et al., 2021) is likely to contribute, at least in part, to $\mathrm{P}$-deficiency-mediated up-regulation of $A O X 1$ gene.

Now, the question is how NO might come into the control of the $-\mathrm{P}$-modulated regulation of $A O X 1$. Under P-deficient conditions, THB2underexpressing strains produce higher levels of NO than WT, and the transcription of PSR1 gene under $\mathrm{P}$ restriction was repressed by NO (Grinko et al., 2021). Therefore, a possible scenario is that the THB2-dependent control of NO is involved in this process. This is the case because the gene $A O X 1$ showed a clear difference between WT and THB2-underexpressing cells under P- deficient conditions as compared with $\mathrm{P}$-replete conditions (Fig. 3, A). Moreover, although AOX1 protein abundance in amiRNA-THB2-cells was not as high as that of WT after 24-48 h of P deprivation, its levels did not show significant difference with WT after longer incubation (Fig. 3, B). These observations emphasize that the effect of NO on $A O X 1$ expression is mediated not only by changes in PSR 1 transcription, which is consistent with the analysis of the psr 1 mutant (Fig. 1, B). Together, the data stress the point that, during acclimation to P limitation, several factors related to NO may contribute to the control of AOX1 expression at the transcriptional and post-transcriptional levels.

It was shown that the AOX pathway could act as a bypass of phosphate control on electron transport (Gonzàlez-Meler et al., 2001). Moreover, $\mathrm{P}$ concentration in plants regulates AOX capacity in coordination with molecular adjustments, functioning to maximize $\mathrm{P}$ acquisition (Del-Saz et al., 2018b). Although P limitation inhibits electron transport through the cytochrome pathway, it simultaneously enhances the capacity of the AOX pathway in WT (Fig. 1, C; Fig. 4). As mentioned above, the AOX respiratory pathway remained unchanged under $P$ deprivation in the psr1 mutant (Fig. 1, C). In the case of amiRNA-THB2 strains, the alternative pathway capacity slightly increased and it occurred with a delay, compared to parental strain (Fig. 4, B). AOX protein levels do not regulate its activity per se (McDonald et al., 2002), but they can limit the extent to which its activity can rise. Hence, the observed increase in AOX1 abundance in the psr 1 mutant and the THB2-transformants (Fig. 1, B; Fig. 3, B) is likely essential to sustain the 
A

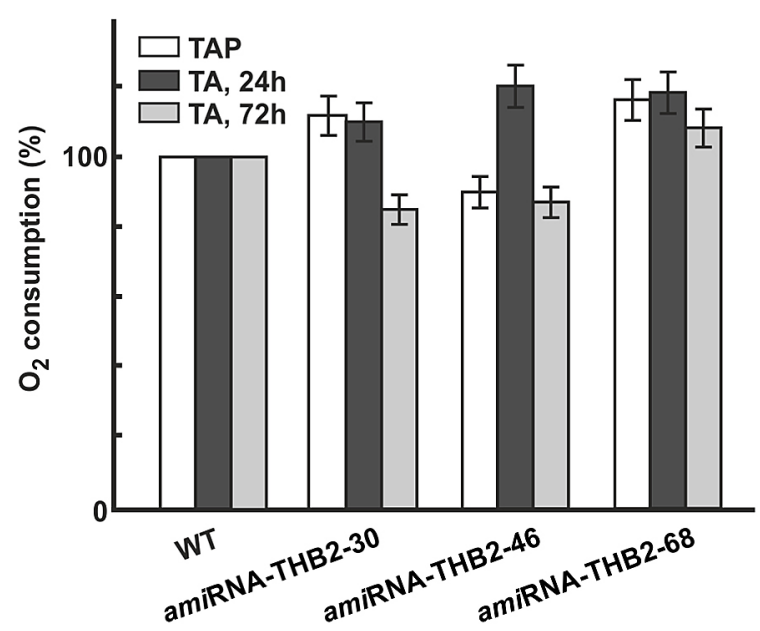

B

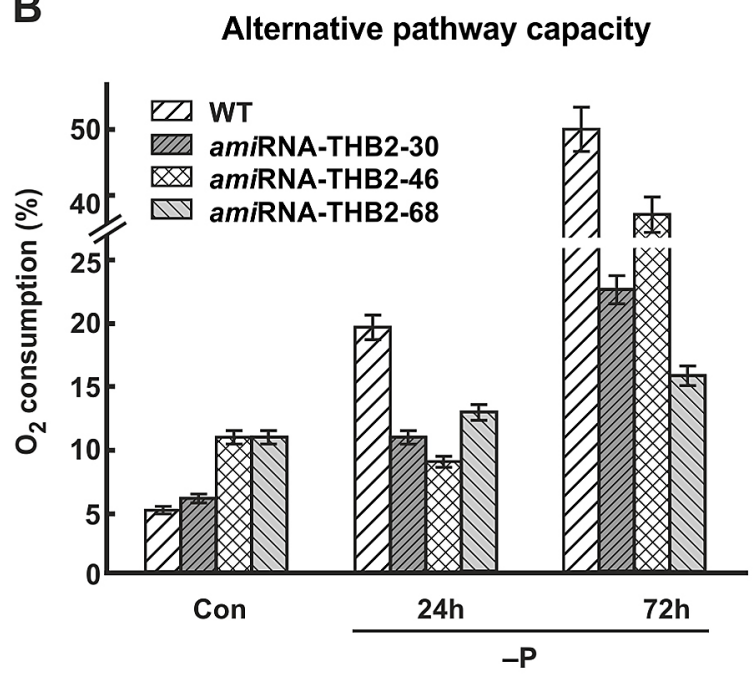

Fig. 4. Oxygen consumption rates in the cw15-325 and amiRNA-THB2 strains subjected to P-depleted conditions. A - Relative total respiration rates in P-replete conditions (TAP) and P-deplete (TA) conditions. The cw15-325 values were considered as 100\%, and the values for the amiRNA-THB2 strains under the same conditions were normalized to the WT values. B - Relative alternative respiration rates in P-replete conditions (Con) and P-deplete conditions. AOX respiration capacity was detected by the sequential addition of $2 \mathrm{mM}$ $\mathrm{KCN}$ and $2 \mathrm{mM} \mathrm{SHAM}$. Total respiration values at each point were considered as $100 \%$ for all strains. $\mathrm{O}_{2}$ uptake rates in the dark were analyzed using a Clark-type $\mathrm{O}_{2}$ electrode. Values represent three biological replicates and at least three technical replicates for each measurement. The data are the means $\pm \mathrm{SE}$.

alternative respiratory pathway on the levels that are vital for the acclimation to P starvation. However, the question of how AOX activity is controlled in Chlamydomonas requires further investigation.

In conclusion, characterization of the AOX 1 control expands our understanding of the regulatory aspects of $\mathrm{P}$-deprivation induced transduction network beyond previously described PSR1dependent transcription of this gene. In this study, we show that AOX1 is tuned at transcriptional and post-transcriptional levels, and NO is an integral part of this regulation.

\section{Acknowledgements}

This work was supported by Russian Science Foundation (21-14-00017).

\section{References}

Affourtit C., Albury M.S., Crichton P.G. and Moore A.L. 2002. Exploring the molecular nature of alternative oxidase regulation and catalysis. FEBS Lett. 510, 121-126.
Baker C.J. and Mock N.M. 1994. An improved method for monitoring cell death in cell suspension and leaf disc assays using Evans blue. Plant Cell, Tissue and Organ Culture. 39, 7-12.

Baurain D., Dinant M., Coosemans N. and Matagne R.F. 2003. Regulation of the alternative oxidase Aox1 gene in Chlamydomonas reinhardtii. Role of the nitrogen source on the expression of a reporter gene under the control of the Aox1 promoter. Plant Physiol. 131, 1418-1430.

Del-Saz N.F., Romero-Munar A., Cawthray G.R.; Aroca R., Baraza E., Flexas J., Lambers H. and Ribas-Carby M. 2017. Arbuscular mycorrhizal fungus colonization in Nicotiana tabacum decreases the rate of both carboxylate exudation and root respiration and increases plant growth under phosphorus imitation. Plant Soil. 416, 97-106.

Del-Saz N.F., Ribas-Carbo M., McDonald A.E., Lambers H., Fernie A.R. and Florez-Sarasa I. 2018a. An in vivo perspective of the role(s) of the alternative oxidase pathway. Trends Plant Sci. 23, 206-219.

Del-Saz N.F., Romero-Munar A., Cawthray G.R., Palma F., Aroca R., Baraza E., FlorezSarasa I., Lambers H. and Ribas-Carby M. 2018b. Phosphorus concentration coordinates a respiratory 
bypass, synthesis and exudation of citrate, and the expression of high-affinity phosphorus transporters in Solanum lycopersicum. Plant Cell Environ. 41, 865-875.

Dinant M., Baurain D., Coosemans N., Joris B. and Matagne R.F. 2001. Characterization of two genes encoding the mitochondrial alternative oxidase in Chlamydomonas reinhardtii. Curr. Genet. 39, 101-108.

Finnegan P.M., Soole K.L. and Umbach A.L. 2004. Alternative mitochondrial electron transport proteins in higher plants. In: Plant Mitochondria: from Gene to Function, Vol. 17. Advances in Photosynthesis and Respiration (Eds: Day D.A., Millar A.H. and Whelan J.). Kluwer, Dordrecht, The Netherlands, pp. 163-230.

Gonzàlez-Meler M.A., Giles L., Thomas R.B. and Siedow J.N. 2001. Metabolic regulation of leaf respiration and alternative pathway activity in response to phosphate supply. Plant Cell Environ. 24, 205-215.

Grinko A., Alqoubaili R., Lapina T. and Ermilova E. 2021. Truncated hemoglobin 2 modulates phosphorus deficiency response by controlling of gene expression in nitric oxide-dependent pathway in Chlamydomonas reinhardtii. Planta. 254, 39.

Laemmli U.K. 1970. Cleavage of structural proteins during the assembly of the head of bacteriophage T4. Nature. 227, 680-685.

Livak K.J. and Schmittgen T.D. 2001. Analysis of relative gene expression data using real time quan-titative PCR and the $2^{-\Delta \Delta C T}$ method. Methods. 25, 402-408.

Maxwell D.P., Nickels R. and McIntosh L. 2002. Evidence of mitochondrial involvement in the transduction of signals required for the induction of genes associated with pathogen attack and senescence. Plant J. 29, 269-279.

McDonald A.E. 2008. Alternative oxidase: an inter-kingdom perspective on the function and regulation of this broadly distributed 'cyanide-resistant' terminal oxidase. Funct. Plant Biol. 35, 535-552.

McDonald A.E., Sieger S.M. and Vanlerberghe G.C. 2002. Methods and approaches to study plant mitochondrial alternative oxidase. Physiol. Plant. 116, 135-143.

McDonald A.E. and Vanlerberghe G.C. 2006. Origins, evolutionary history, and taxonomic distribution of alternative oxidase and plastoquinol terminal oxidase. Comp. Biochem. Physiol. Part D Genomics Proteomics. 1, 357-364.

Millar A.H., Whelan J., Scoole K.L. and Day D.A. 2011. Organization and regulation of mito- chondrial respiration in plants. Annu. Rev. Plant Biol. 62, 79-104.

Molen T.A., Rosso D., Piercy S. and Maxwell D.P. 2006. Characterization of the alternative oxidase of Chlamydomonas reinhardtii in response to oxidative stress and a shift in nitrogen source. Physiol. Plantarum. 127, 74-86.

Moseley J.L., Chang C-W. and Grossman A.R. 2006. Genome-based approaches to understanding phosphorus deprivation responses and PSR1 control in Chlamydomonas reinhardtii. Eukaryot. Cell. 5, 26-44.

Moseley J.L., Gonzalez-Ballester D., Pootakham W., Bailey S. and Grossman A.R. 2009. Genetic Interactions between regulators of Chlamydomonas phosphorus and sulfur deprivation responses. Genetics. 181, 889-905.

Ostroukhova M., Zalutskaya Z. and Ermilova E. 2017. New insights into $A O X 2$ transcriptional regulation in Chlamydomonas reinhardtii. Eur. J. Protistol. 58, 1-8.

Popov N., Schmitt M., Schulzeck S. and Matthies H. 1975. Reliable micromethod for determination of the protein content in tissue homogenates. Acta Biol. Med. Ger. 34, 1441-1446.

Quesada A., Hidalgo J. and Fernandez E. 1998. Three Nrt2 genes are differentially regulated in Chlamydomonas reinhardtii. Mol. Gen. Genet. 258, 373-377.

Royo B., Moran J.F., Ratcliffe R.G. and Gupta K.J. 2015. Nitric oxide induces the alternative oxidase pathway in Arabidopsis seedlings deprived of inorganic phosphate. J. Exp. Bot. 66, 6273-6280.

Selinski J., Scheibe R., Day D.A. and Whelan J. 2018. Alternative oxidase is positive for plant performance. Trends Plant Sci. 23, 588-597.

Van Aken O., Giraud E., Clifton R. and Whelan J. 2009. Alternative oxidase: a target and regulator of stress responses. Physiol. Plant. 137, 354-361.

Vanlerberghe G.C. 2013. Alternative oxidase: a mitochondrial respiratory pathway to maintain metabolic and signaling homeostasis during abiotic and biotic stress in plants. Int. J. Mol. Sci. 14, 6805 $-6847$.

Vanlerberghe G.C., Cvetkovska M. and Wang J. 2009. The maintenance of homeostatic mitochondrial signaling during stress a physiological role for alternative oxidase? Physiol. Plant. 137, 392-406.

Wykoff D.D., Davies J.P., Melis A. and Grossman A.R. 1998. The regulation of photosynthetic electron transport during nutrient deprivation in Chlamydomonas reinhardtii. Plant Physiol. 117, 129-139. 
Zalutskaya Z., Filina V., Ostroukhova M. and Ermilova E. 2018. Regulation of alternative oxidase 1 in Chlamydomonas reinhardtii during sulfur starvation. Eur. J. Protistol. 63, 26-33.

Zalutskaya Z., Lapina T. and Ermilova E. 2015. The Chlamydomonas reinhardtii alternative oxidase 1 is regulated by heat stress. Plant Physiol. Biochem. 97, 229-234.
Zalutskaya Z., Ostroukhova M. and Ermilova E. 2016. The Chlamydomonas alternative oxidase 1 is regulated by cadmium stress: new insights into control of expression. Environ. Exp. Bot. 130, 133-140.

Zalutskaya Z., Ostroukhova M., Filina V. and Ermilova E. 2017. Nitric oxide upregulates expression of alternative oxidase 1 in Chlamydomonas reinhardtii. J. Plant Physiol. 219, 123-127.

Address for correspondence: Elena Ermilova. Department of Microbiology, St. Petersburg State University, Universitetskaya Emb.7/9, 199034 St. Petersburg, Russia; e-mail: e.ermilova@spbu.ru 